\title{
Molecular basis of mild hyperphenylalaninaemia in Poland
}

\author{
Cezary Żekanowski, Maria Nowacka, Barbara Cabalska, Jerzy Bal
}

\begin{abstract}
The major cause of the different forms of hyperphenylalaninaemia (HPA) is mutations in the gene encoding phenylalanine hydroxylase (PAH). The aim of this study was to determine the mutations responsible for mild forms of HPA and to relate different clinical phenotypes of HPA patients to their PAH genotypes. Four "mild" mutations, including the most frequent $\mathrm{A403V}$ and $\mathrm{R} 297 \mathrm{H}$ mutations, occurred exclusively in mild hyperphenylalaninaemia (MHP). Mutations A104D, R243Q, R241H, and Y414C were detected in patients with mild phenylketonuria (mild PKU) only. These results may be useful in establishing a molecular differential diagnosis for PAH deficiency in Poland.
\end{abstract}

$(\mathcal{M}$ Med Genet 1997;34:1035-1036)

Keywords: mild hyperphenylalaninaemia; phenylketonuria; $\mathrm{PAH}$ gene

Phenylketonuria (PKU) is caused by a deficiency of hepatic phenylalanine hydroxylase (OMIM 261600). PAH deficiency is phenotypically heterogeneous as shown in neonatal screening. Mild forms of hyperphenylalaninaemia can be divided clinically into (1) mild PKU with blood phenylalanine levels of $600-1200$ $\mu \mathrm{mol} / 1$ and (2) non-PKU HPA (MHP) with concentrations below $600 \mu \mathrm{mol} / 1 .{ }^{1}$ In Poland, the frequency of MHP and mild PKU is approximately $30 \%$ of total HPA. ${ }^{2}$

A total of 316 mutations in the PAH gene have been identified so far. ${ }^{3}$ Different mutations cause a wide spectrum of in vitro enzyme activities which correlate with the different phenotypes observed. According to phenotypic effects, "severe" and "mild" mutations in the PAH gene can be differentiated. ${ }^{45}$ The purpose of this study is to determine the molecular basis of mild forms of hyperphenylalaninaemia in Poland and to correlate the mutations detected with clinical phenotypes.

Genomic DNA was isolated from total blood of $34 \mathrm{MHP}$ and eight mild PKU probands from unrelated Polish families. All patients were detected through Guthrie newborn screening. Quantitative estimations of phenylalanine concentrations were made if mild hyperphenylalaninaemia was found to be persistent. Serum phenylalanine levels were determined fluorimetrically for the first time at an average age of 2-4 months. The patients were classified according to Güttler. ${ }^{1}$ All mild PKU patents were on a diet with partially restricted phenyla- lanine intake. All the MHP patients were without dietary restrictions.

Routine screening for seven common mutations (Y414C, R408W, IVS12ntlg $\rightarrow$ a (IVS12), IVS10nt-11g $\rightarrow$ a (IVS10), R261Q, R252W, and R158Q) was performed as described previously. ${ }^{6}$ Then SSCP analysis of PAH exons with flanking sequences and direct sequencing (Sequenase 2.0 and $\Delta T a q$ ) was performed.

Three novel mutations were identified in the group studied, IVS2nt5g $\rightarrow \mathrm{a} \quad(168+5 \mathrm{~g} \rightarrow \mathrm{a}$, IVS2), IVS4nt5g $\rightarrow \mathrm{t}(441+5 \mathrm{~g} \rightarrow \mathrm{t}$, IVS4), and D222G (GAT $\rightarrow$ GGT). All the patients were compound heterozygotes for "severe" and

Table 1 Genotype-phenotype relations in MHP and mild PKU patients

\begin{tabular}{|c|c|c|}
\hline Genotype & $\begin{array}{l}\text { Pretreatment } \\
\text { phenylalanine } \\
\text { level }(\mu \text { molll })\end{array}$ & $\begin{array}{l}\text { Phenylalanine } \\
\text { concentrations } \\
\text { Range ( } \mu \text { molll) }\end{array}$ \\
\hline \multicolumn{3}{|c|}{ Mild phenylketonuria (patients on diet) } \\
\hline $\mathrm{A} 104 \mathrm{D} / \mathrm{D} 222 \mathrm{G}^{\star}$ & 545 & $\begin{array}{l}\text { 121-605 } \\
\text { (borderline) }\end{array}$ \\
\hline R241H/R252W & 454 & $242-484$ \\
\hline R241H/IVS10 & 793 & $242-484$ \\
\hline $\mathrm{R} 241 \mathrm{H} / \mathrm{R} 408 \mathrm{~W}$ & 484 & $278-696$ \\
\hline R243Q/A104D & 854 & $726-1211$ \\
\hline $\mathrm{R} 243 \mathrm{Q} /$ ? & 1138 & $121-726$ \\
\hline Y414C/A104D & 1453 & $\begin{array}{l}121-605 \text { (rapid } \\
\text { normalisation) }\end{array}$ \\
\hline Y414C/R408W & 3190 & $\begin{array}{r}121-1200 \text { (rapid } \\
\text { normalisation) }\end{array}$ \\
\hline \multicolumn{3}{|c|}{ Mild hyperphenylalaninaemia (patients off diet) } \\
\hline F55L/IVS10 & 345 & $303-605$ \\
\hline P89/R408W & 672 & $\begin{array}{l}\text { 605-726 } \\
\text { (borderline) }\end{array}$ \\
\hline P211T/R408W & 400 & $484-726$ \\
\hline V245A/R252W & 442 & $484-605$ \\
\hline V245A/R408W & 394 & $242-394$ \\
\hline R297H/IVS2* & 363 & $363-484$ \\
\hline R297H/R252W & 484 & $484-726$ \\
\hline R297H/R408W & 394 & $242-660$ \\
\hline R297H/R408W & 387 & $333-424$ \\
\hline $\mathrm{R} 297 \mathrm{H} / \mathrm{R} 408 \mathrm{~W}$ & 327 & $272-430$ \\
\hline R297H/R408W & 527 & $242-484$ \\
\hline A300S/IVS4* ${ }^{\star}$ & 272 & $242-484$ \\
\hline A300S/R158Q & 605 & $363-605$ \\
\hline A300S/R158Q & 363 & $242-896$ \\
\hline A 300 S/R408W & 309 & $363-484$ \\
\hline A300S/R408W & 327 & $484-605$ \\
\hline I306V/R408W & 563 & $363-605$ \\
\hline I306V/R408W & 605 & $363-605$ \\
\hline I306V/R408W & 642 & $484-666$ \\
\hline T380M/R408W & 339 & $363-484$ \\
\hline T380M/R408W & 339 & $242-363$ \\
\hline $\mathrm{A} 403 \mathrm{~V} / \mathrm{R} 158 \mathrm{Q}$ & 490 & $242-363$ \\
\hline A403V/P281L & 339 & $363-605$ \\
\hline A403V/IVS10 & 303 & $242-605$ \\
\hline A403V/IVS10 & 448 & $363-605$ \\
\hline A403V/R408W & 611 & $363-484$ \\
\hline A403V/R408W & 496 & $363-484$ \\
\hline A403V/R408W & 260 & $363-484$ \\
\hline A403V/R408W & 327 & $236-448$ \\
\hline A403V/R408W & 381 & $363-605$ \\
\hline A403V/R408W & 490 & $260-496$ \\
\hline A403V/R408W & 484 & $363-605$ \\
\hline A403V/R408W & 605 & $363-605$ \\
\hline A403V/R408W & 300 & $260-605$ \\
\hline
\end{tabular}

Mild and moderate mutations are shown first. Novel mutation are marked with an asterisk.
Received 15 January 1997 publication 13 May 1997 
"mild" mutations. The genotypic and phenotypic data obtained for the patients are summarised in table 1 .

In the MHP group, A403V and R297H were the most frequent "mild" mutations. Mutations A403V, A300S, and $\mathrm{R} 297 \mathrm{H}$ were not detected in a group of 140 classical PKU patients (data not shown) or in mild PKU patients. Mutation A403V has been detected previously in southern Europe, and in Spain it is a relatively common mutation $(14 \%){ }^{7}$ In the group reported here its frequency is even higher $(19 \%)$, but the limited number of cases does not allow significant statistical comparison. In both countries it has been detected in combination with "severe" mutations (R408W, $\mathrm{R} 252 \mathrm{~W}){ }^{8} \mathrm{R} 297 \mathrm{H}$ has been identified in the USA with no indication of its severity. ${ }^{3}$ In the MHP group, however, it is connected with "severe" mutations, known to cause classical homozygous PKU (R408W, R252W). It is postulated that $\mathrm{A} 403 \mathrm{~V}$ and $\mathrm{R} 297 \mathrm{H}$ could both be unambiguously ascribed to a "mild" group.

A rare mutation, F55L, was detected in a patient with MHP; it occurred with an IVS10nt-1 $1 \mathrm{~g} \rightarrow$ a mutation, known to produce a classical homozygous PKU phenotype. ${ }^{3}$ A patient with P89S/R408W presented a borderline MHP phenotype, with relatively high phenylalanine levels and stable high IQ scores and it is postulated that P89S is a "mild" mutation.

The next four mutations (Y414C, R243Q, $\mathrm{R} 241 \mathrm{H}$, and A104D) occurred exclusively with mild PKU. The SSCP patterns indicate that these mutations are absent in a group of 140 classical PKU patients.

An A104D/D222G patient had a mild PKU phenotype with high phenylalanine tolerance $(50 \mathrm{mg} / \mathrm{kg} /$ day) and normal IQ scores at the age of 2 years. Precise assessment of D222G "severity" requires identification of other patients bearing this mutation.

The novel splicing mutations (IVS2 and IVS4) were "severe" ones and when combined with mild mutations (R297H and A300S, respectively) produced a MHP phenotype.

The results presented provide preliminary data on the molecular basis of mild forms of hyperphenylalaninaemia in Poland. Identification of relatively frequent mutations connected with either MHP or mild PKU enables neonatal differential genotyping of HPA and identification of patients not requiring dietary therapy..$^{9} 10$

1 Güttler F. Hyperphenylalaninemia: diagnosis and classification of various types of phenylalanine hydroxylase deficiency in childhood. Acta Paediatr Scand Suppl 1980;280:1-80.

2 Cabalska B, Sendecka E, Nowaczewska I, Zorska K. Mild hyperphenylalaninemia - frequency, physical and mental development (in Polish). Pediatr Pol 1994;59:339-44

3 Byck S, Nowacki P, Prevost L, Scriver CR. PAH Mutation Analysis Consortium Newsletter. Winter 1997.

4 Economou-Petersen E, Henriksen KF: Guldberg P Güttle F. Molecular basis for nonphenylketonuria hyperphenylaaninemia. Genomics 1992;14:1-5.

5 Güttler F, Guldberg P, Henriksen I, et al. Molecular basis for the phenotypic diversity of phenylketonuria and related hyperphenylalaninemias. F Inherit Metab Dis 1993;16:602-

6 Żekanowski C, Nowacka M, Żygulska M, et al. Frequencies of the most common mutations responsible for phenylketonuria in Poland. Mol Cell Probes 1994;8:323-4.

7 Desviat LR, Perez B, Ugarte M. Molecular basis of non-PKU hyperphenylalaninemia in Spain: prevalence of A403V, a mutation with high residual activity. F Inherit Metab Dis 1996;19:227-30.

8 Romano V, Guldberg P, Güttler F, et al. PAH deficiency in Italy: correlation of genotype with phenotype in the Sicilian Italy: correlation of genotype with phenotype in

9 Güttler F, Guldberg P. Mutations in the phenylalanine hydroxylase gene: genetic determinants for the phenotypic hydroxylase gene: genetic determinants for the phenotypic variability of hyperphenyl

10 Lichter-Konecki U, Rupp A, Konecki DS, et al. Relation between phenylalanine hydroxylase genotypes and phenotypic parameters of diagnosis and treatment of hyperphenylalaninemic disorders. F Inherit Metab Dis 1994;17:362-5. 